\title{
Journal of Japanese Linguistics \\ Vol. 24 (2008)
}

\section{Contents}

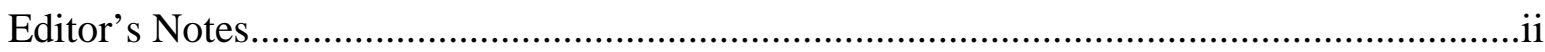

\section{$\underline{\text { Regular articles }}$}

Remarks on focus feature organization in narrow syntax with special reference to

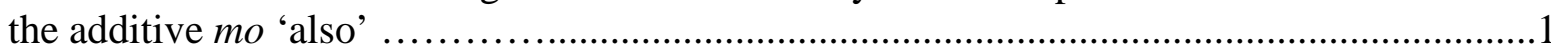
Koji Hoshi

Constraints on nominative-case marking in te hosi constructions: A PIC account .45 Akiko Kobayashi

Quantifier position in Japanese and the domains of specificity and indefiniteness 69 Harumi Minagawa

Verb movement in Japanese revisited. .89

Yuji Hatakeyama, Kensuke Honda and Kosuke Tanaka 